\title{
Dermatology
}

\section{Glycemic Control in the Treatment of Psoriasis}

\author{
Wilfred Ip ${ }^{\mathrm{a}} \quad$ Mark G. Kirchhof ${ }^{\mathrm{b}}$

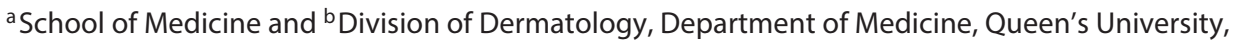 \\ Kingston, ON, Canada
}

\section{Keywords}

Psoriasis vulgaris - Plaque psoriasis · Pioglitazone . Metformin · Liraglutide · Exenatide · Sitagliptin ·

Antihyperglycemic agents

\begin{abstract}
Psoriasis is a common chronic inflammatory skin disease that manifests as scaly erythematous plaques as a consequence of keratinocyte hyperproliferation and inflammation. It is commonly associated with diabetes, obesity, and the metabolic syndrome. While there are numerous approved treatment options available, they have limitations including availability, toxicities such as immunosuppression, and high cost. There is increasing evidence to suggest that several hypoglycemic agents used in the treatment of type 2 diabetes, including glucagon-like peptide-1 receptor agonists, dipeptidyl peptidase-4 inhibitors, thiazolidinediones and biguanides, exert beneficial effects in psoriasis. In this review, we summarize the growing evidence supporting the therapeutic role of hypoglycemic agents in psoriasis and discuss the potential underlying mechanisms. We suggest that dermatologists consider the use of hypoglycemic agents in psoriasis especially in cases with coexisting diabetes and in cases in which immunosuppression is contraindicated. Earlier referral to endocrinology in patients with concomitant diabetes may be appropriate.

๑) 2017 S. Karger AG, Basel
\end{abstract}

() 2017 S. Karger AG, Basel

\section{Introduction}

Psoriasis is a common chronic inflammatory skin disease involving keratinocyte hyperproliferation and inflammation. Affecting approximately $2-3 \%$ of the Western population [1], psoriasis is a life-long disease associated with significant morbidity [2]. Patients with psoriasis have an increased risk of new-onset diabetes [3]. Conversely, there is an elevated risk of new-onset psoriasis in patients with diabetes [4]. The strong association between psoriasis and diabetes suggests a common inflammatory pathophysiology [5].

Although psoriasis has no cure, various topical and systemic treatments for psoriasis currently exist. However, many of these treatments are costly and have toxicities including immunosuppression. As such, there is a need for the development of therapies that are effective and carry fewer side effects with lower cost.

There is increasing evidence of the beneficial effects of antidiabetic hypoglycemic agents in psoriasis including glucagon-like peptide-1 (GLP-1) receptor agonists, dipeptidyl peptidase-4 (DPP-4) inhibitors, thiazolidinediones, and biguanides. In this review, we summarize the clinical data demonstrating antipsoriatic effects of these hypoglycemic agents and discuss the potential underlying mechanisms. Therapeutics that effectively treat both psoriasis and diabetes simultaneously and are nonimmu-

\section{KARGER}

E-Mail karger@karger.com

www.karger.com/drm
Mark G. Kirchhof, MD, PhD

Division of Dermatology, Department of Medicine, Queen's University 166 Brock Street

Kingston, ON K7L 5G2 (Canada)

E-Mailmgk2@queensu.ca 
nosuppressive would be attractive additions to the treatment ladder of the dermatologist and endocrinologist alike.

\section{GLP-1 Receptor Agonists}

GLP-1 is an incretin hormone secreted postprandially by intestinal endocrine $L$ cells that primarily stimulates the secretion of insulin from pancreatic $\beta$-cells. Several agonists of the GLP-1 receptor have been developed for the treatment of diabetes including exenatide and liraglutide.

\section{Clinical Reports}

Exenatide treatment for 2 weeks in one report led to a reduction in the Psoriasis Area and Severity Index (PASI) by 5.5 , an effect that was completely reversed upon discontinuation of therapy. In this same report, liraglutide was administered and similarly produced a reduction in PASI within 3 weeks [6].

Several subsequent reports similarly demonstrated improvements in psoriasis with exenatide or liraglutide treatment [6-11]. In one study, acitretin for 4 months was ineffective, but improved PASI and Dermatology Life Quality Index were seen after liraglutide had been initiated [8]. Prospective case series studies demonstrated significant improvements in PASI and epidermal thickness within 7 weeks of GLP-1 receptor agonist treatment in comparison to baseline $[9,11]$.

Contradicting these positive results, a randomized controlled trial conducted in patients with psoriasis and obesity showed no statistically significant difference in either PASI or Dermatology Life Quality Index with liraglutide treatment in comparison to placebo [12]. The liraglutide-treated group, however, showed significant improvement in PASI in comparison to baseline with a mean reduction of 2.6 after 8 weeks [12]. Despite this study result, the overall evidence suggests a beneficial effect of GLP-1 receptor agonists in psoriasis.

\section{Mechanisms}

GLP-1 receptor agonists cause weight loss, and weight loss leads to improvement of psoriasis $[13,14]$. It follows that GLP-1 receptor agonists may improve psoriasis indirectly via weight loss. Indeed, all of the patients studied in the above clinical reports demonstrated weight loss [611]. However, clinical improvement of psoriasis was achieved prior to any changes in weight $[6,9-11]$. In a case series of 7 psoriasis patients treated with liraglutide, no correlation was observed between weight loss and PASI [9]. Therefore, although it is plausible that GLP-1 receptor agonists may improve psoriasis via weight loss, GLP-1 receptor agonists likely exert beneficial effects irrespective of weight loss. Further support of this notion stems from patients receiving gastric bypass surgery, a procedure which causes a large increase in circulating GLP-1 levels, who demonstrated improvement in psoriasis prior to any weight loss, as reviewed elsewhere [15].

On the other hand, GLP-1 receptor agonists are also known to reduce appetite and food intake. Fasting alone without weight loss resulted in improvement of psoriasis [16]. A low-calorie diet for 4 weeks improved psoriasis independently of any changes in weight [17]. These data suggest that the reduction of energy consumption is a potential mechanism by which GLP-1 receptor agonists may improve psoriasis.

As another plausible mechanism, GLP-1 receptor agonists may indirectly alleviate psoriasis via improvement in glycemic control. However, a case series study showed no correlation between PASI changes and $\mathrm{HbA}_{1 \mathrm{c}}$ levels [9]. Many reports have shown PASI improvement in patients already possessing good glycemic control [10]. Improvement in $\mathrm{HbA}_{1 \mathrm{c}}$, a long-term indicator of glycemic control, was seen after 18 weeks of treatment with liraglutide in some of the patients who demonstrated an improved PASI after 7 weeks [9]. Unfortunately, fasting plasma glucose levels were not measured. Whether GLP1 receptor agonist therapy can alleviate psoriasis through glycemic control is therefore questionable.

GLP-1 receptor agonists may also exert direct actions in psoriatic skin lesions. The GLP-1 receptor was detected in mouse epidermis adjacent to hair follicles and in skinderived cultured cells [18]. However, although GLP-1 receptor expression was detected in human psoriatic plaques, only 1 of 6 biopsies from unaffected skin showed detectable GLP-1 receptor expression [19]. GLP-1 receptor expression also could not be detected in cultured human keratinocytes [19]. It is thus more likely that any detectable GLP-1 receptor is due to the infiltration of other cells from the blood. This is further supported by positive GLP-1 receptor expression in the blood of both healthy volunteers and psoriasis patients [19].

While the GLP-1 receptor may not be expressed on keratinocytes, it was found to be expressed on invariant natural killer $\mathrm{T}$ cells [6]. These cells were shown to divert from the general circulation to infiltrate psoriatic lesions [20-22]. Liraglutide therapy reduced both the invariant natural killer T cell number and the secretion of inflammatory cytokines in psoriatic lesions while correspond-
24

Dermatology 2017;233:23-29

DOI: $10.1159 / 000472149$
Ip/Kirchhof 
ingly repopulating the number of invariant natural killer $T$ cells in the general circulation $[6,9,11]$. Tumor necrosis factor- $\alpha$ (TNF- $\alpha)$-producing monocytes were also reduced by $53 \%$ in the circulation whereas $\mathrm{T}$ cells, B cells, and natural killer cells remained unchanged [11]. In addition, $\gamma \delta$ T-cell numbers and levels of interleukin-17 mRNA produced from dermal CD3+ cells were higher in psoriatic lesions and subsequently reduced upon treatment with GLP-1 receptor agonists [9]. Evidence in other systems supports the role of GLP-1 receptor agonists in reducing inflammation [23-25]. Taken together, the mechanism by which GLP-1 receptor agonists improve psoriasis involves the diversion of immune cells from psoriatic lesions to reduce inflammation.

\section{DPP-4 Inhibitors}

Whereas GLP-1 receptor agonists mimic the action of GLP-1, DPP-4 inhibitors exert their effect by preventing the degradation of endogenous GLP-1 by DPP-4. Several DPP-4 inhibitors have been marketed for diabetes treatment including sitagliptin, teneligliptin, and linagliptin.

\section{Clinical Reports}

The first report of antipsoriatic effects of DPP-4 inhibitors was published in 2012 and showed remission of psoriatic lesions following sitagliptin therapy for 3 months [26]. Since then, several other reports have similarly described improvement in psoriasis after treatment with sitagliptin or teneligliptin [27, 28]. A large-scale population-based retrospective study found that DPP-4 inhibitor therapy led to a reduced incidence of autoimmune disorders including psoriasis [29].

On the other hand, there was a single case of a patient starting on sitagliptin who suffered a psoriasiform eruption. However, the eruption later resolved despite continued treatment with sitagliptin [30].

\section{Mechanisms}

It is questionable whether the mechanism by which DPP-4 inhibitors benefit psoriasis involves glycemic control. In 1 patient, improvement in psoriasis and $\mathrm{HbA}_{1 \mathrm{c}}$ occurred simultaneously [28]. However, some patients demonstrated improvement in psoriasis without any change in $\mathrm{HbA}_{1 \mathrm{c}}$ levels $[26,28]$.

As DPP-4 inhibitors increase circulating GLP-1 levels, the same mechanisms as discussed for GLP-1 receptor agonists may similarly apply. However, DPP-4 is a ubiquitously expressed transmembrane glycoprotein, also

Glycemic Control and Psoriasis known as CD26, which has a multitude of functions besides GLP-1 degradation.

DPP-4 is expressed on keratinocytes [31, 32]. DPP-4 expression and activity are upregulated in psoriatic lesions compared to uninvolved skin and healthy volunteer skin $[32,33]$. It was additionally shown that DPP-4 expression is elevated prior to the development of an overt psoriatic lesion and concentrated primarily towards the basal layers of a psoriatic lesion, suggesting its involvement in the pathogenesis of a psoriatic lesion [33]. DPP-4 inhibitor treatment decreased keratinocyte proliferation in vitro and partially restored keratinocyte differentiation in vivo [34]. Thus, DPP-4 inhibitors may alleviate psoriasis by inhibiting keratinocyte proliferation.

In addition, some studies suggest that DPP-4 inhibitors are anti-inflammatory as sitagliptin rapidly reduced several inflammatory factors in humans [35-37]. Sitagliptin prevented the DPP-4-mediated increase in TNF- $\alpha$ expression in monocytes as well as Racl activation and T-cell migration $[38,39]$. DPP-4 is also a marker of T-cell and monocyte activation and has been shown to be an indicator of autoimmune diseases [40]. There have been conflicting reports, however, showing that sitagliptin has no effect on C-reactive protein levels [41, 42].

In psoriasis, it has been demonstrated that the epidermis and dermis of lesions are infiltrated by DPP-4-positive T cells, and there is increased DPP-4 expression in psoriatic skin fibroblasts $[32,43]$. There is, however, one report of decreased T cell DPP-4 expression in psoriasis [44]. DPP-4 levels and activity have also been shown to be elevated in the $\mathrm{T}$ cells of type 2 diabetes patients [45]. Th17 cells also express DPP-4 [46]. Although there is some evidence suggesting that DPP-4 inhibitors possess anti-inflammatory properties that may benefit psoriasis, further studies are necessary to clarify the mechanistic role of DPP-4.

\section{Thiazolidinediones}

As a specific ligand for nuclear peroxisome proliferator-activated receptor- $\gamma$ (PPAR- $\gamma$ ), thiazolidinediones increase insulin sensitivity and thus lower blood glucose. Although troglitazone, rosiglitazone, and pioglitazone have been available to patients, troglitazone has been removed from the market due to hepatotoxicity.

\section{Clinical Reports}

In 1998, an open-label study using troglitazone in 3 patients with type 2 diabetes and concomitant psoriasis demonstrated significant psoriasis improvement togeth-

Dermatology 2017;233:23-29 
er with improved glycemic control [47]. One patient remained in remission 8 weeks following therapy discontinuation [48]. Many subsequent clinical studies showed that pioglitazone or rosiglitazone therapy also have antipsoriatic effects [49-54]. A double-blinded randomized controlled trial of pioglitazone discovered a significant dose-dependent reduction in PASI within 2 weeks of treatment without adverse effects [55]. Another recent open-label randomized controlled trial demonstrated that treatment with pioglitazone significantly improved psoriasis in patients with a concomitant metabolic disorder [56]. Furthermore, patients with psoriatic arthritis showed improvement in psoriatic plaques and joint pain with pioglitazone therapy [57].

Interestingly, one double-blinded randomized controlled study showed that pioglitazone conferred additional benefits when administered together with acitretin [51], while another randomized controlled trial demonstrated benefits of pioglitazone as an adjunct to methotrexate [52]. Importantly, a lower dosage of methotrexate (15 mg/week) in combination with pioglitazone produced a PASI-75 similar to studies using high methotrexate dosage alone (22.5 mg/week) [58]. These results highlight the possibility that thiazolidinediones, when used in combination with standard therapies, can help achieve an additional clinical benefit with reduced toxic dosages.

A large retrospective population-based case-control study identified a statistically significant reduction in psoriasis incidence with thiazolidinedione usage versus no usage, suggesting that thiazolidinediones can lower the risk of acquiring psoriasis [59]. Moreover, a recent population-based Taiwanese cohort study demonstrated that frequent usage of thiazolidinediones in patients with diabetes conferred a modest reduction in psoriasis risk [4].

Despite all of these reports of beneficial effects of thiazolidinediones in psoriasis, 2 large-scale randomized double-blinded multicenter controlled trials failed to show a statistically significant effect of rosiglitazone on psoriasis severity, although trends were observed [60]. The authors highlighted the existence of a very large placebo effect, the partial concurrent usage of topical corticosteroids, and a possibility of inadequate dosage of rosiglitazone as reasons for a lack of observed significance. Nevertheless, a 2012 meta-analysis of the small number of clinical trials available concluded that oral pioglitazone has a modest beneficial effect in plaque psoriasis [61].

Of note, a single pilot study attempted using topical $0.5 \%$ rosiglitazone but failed to show any effect on psoriatic plaques after 30 days, suggesting that topical thiazolidinediones are ineffective [62].

\section{Mechanisms}

The most obvious mechanism underlying the antipsoriatic effects of thiazolidinediones relies on their role as specific ligands for PPAR- $\gamma$. PPAR- $\gamma$ is a member of the nuclear hormone receptor family of which many other members including glucocorticoid, retinoid, and vitamin $D$ have proved to be effective targets in the treatment of psoriasis. PPAR- $\gamma$ is expressed in human keratinocytes [48]. Treatment of cultured psoriatic human keratinocytes with PPAR- $\gamma$ ligands inhibited proliferation, and troglitazone was shown to inhibit keratinocyte proliferation in vitro and reduce epidermal hyperplasia in a mouse model of psoriasis $[48,63,64]$. Interestingly, topical application of thiazolidinediones in mice reduced epidermal keratinocyte proliferation and thickness $[65,66]$. This suggests that thiazolidinediones possess antiproliferative properties in keratinocytes.

Thiazolidinediones may also benefit psoriasis by reducing inflammation via PPAR- $\gamma$. The role of PPAR- $\gamma$ in the inhibition of inflammation via action in various immune cells is well documented [67]. In the oxazolonesensitized mouse model of allergic contact dermatitis, oral or topical treatment with a water-soluble lipoic acidbased thiazolidinedione named BP-1017 produced antiinflammatory effects [64]. Thiazolidinediones and other PPAR- $\gamma$ agonists inhibited the secretion of a variety of inflammatory cytokines from $\mathrm{T}$ lymphocytes and macrophages, such as TNF- $\alpha$, which is an important pathogenic mechanism in psoriatic lesions [68-70].

Whether glycemic control is another mechanism by which thiazolidinediones improve psoriasis is refuted by the reports in nondiabetic euglycemic insulin-sensitive individuals of improved psoriasis with thiazolidinedione treatment [48]. However, given the increasing evidence of an association between psoriasis and insulin resistance [71], it remains to be determined whether insulin sensitization by thiazolidinediones contributes to the relief of psoriasis. One clinical trial in patients with both metabolic disorder and psoriasis demonstrated simultaneous improvements in psoriasis and glucose levels, among other metabolic parameters [56].

\section{Biguanides}

Biguanides include the first-line type 2 diabetes oral hypoglycemic agent metformin, which primarily lowers blood glucose by inhibiting hepatic glucose production and increasing insulin sensitivity via an AMP-activated protein kinase-dependent mechanism.
26

Dermatology 2017;233:23-29

DOI: $10.1159 / 000472149$
Ip/Kirchhof 


\section{Clinical Reports}

A retrospective case-control study examined the incidence of psoriasis in diabetes patients and found a statistically significant reduction with metformin treatment versus no metformin treatment [59]. This suggests that metformin therapy can lower the risk of psoriasis development at least in patients with diabetes. A populationbased study also demonstrated that frequent usage of metformin reduced the incidence of new-onset psoriasis in patients with diabetes [4]. A single open-label randomized controlled trial demonstrated statistically significant improvement of psoriasis with metformin treatment in comparison to placebo in patients with a concomitant metabolic disorder [56].

On the other hand, there is a single report of a psoriasiform drug eruption with metformin treatment that was relieved upon discontinuation of therapy [72].

\section{Mechanisms}

AMP-activated protein kinase has been shown to exert anti-inflammatory effects in macrophages and T cells [73, 74]. There have been reports of metformin treatment leading to a reduction in inflammatory markers and cytokines including TNF- $\alpha$, interferon- $\gamma$, and C-reactive protein [74, 75]. In keratinocytes, metformin has been shown to inhibit proliferation via the mitogen-activated protein kinase pathway [76]. Moreover, metformin inhibited proliferation and proinflammatory cytokines via the mammalian target of rapamycin signaling pathway in cultured human keratinocytes [77]. Clearly, additional clinical studies are required to ascertain the relevance of metformin therapy in psoriasis patients with or without metabolic disorder.

\section{Conclusion}

There is ample clinical evidence to suggest that several classes of hypoglycemic agents benefit psoriasis. We suggest that the various hypoglycemic agents exert antipsoriatic effects independently of weight loss and glycemic control by targeting keratinocyte proliferation and skin inflammation pathways.

The major advantages of hypoglycemic agents over traditional antipsoriatic medications include favorable side effect profiles. Whereas the majority of successful antipsoriatic medications are immunosuppressive, none of the hypoglycemic agents show evidence of suppression of the immune system [78-81]. These medications are frequently used in the diabetic population without complication, and the side effects are well tolerated.

Glycemic Control and Psoriasis
In terms of side effects, GLP-1 receptor agonists are frequently associated with weight loss and gastrointestinal upset. They are contraindicated in patients with renal insufficiency. Commonly reported side effects of DPP-4 inhibitors include headache, gastrointestinal upset, nasopharyngitis, and upper respiratory tract infection. However, the long-term safety of both GLP-1 receptor agonists and DPP-4 inhibitors has not been established, and they have both been shown to be associated in rare instances with acute pancreatitis [82]. The side effects of thiazolidinediones include fluid retention and weight gain. There is concern that thiazolidinediones may increase the risk of congestive heart failure, cardiovascular events, fractures, and bladder cancer; however, these risks are small. Metformin is associated with gastrointestinal upset and rarely with lactic acidosis. It is contraindicated in renal insufficiency.

Clinicians should appreciate the limitations of the current data on hypoglycemic agents. There are few studies demonstrating the beneficial effects of hypoglycemic agents in psoriasis conducted in nondiabetic individuals [48]. In addition, the current data are largely derived from case reports, case series, and small clinical trials that are poorly controlled or nonblinded. Follow-up lengths are far too short to evaluate the long-term effects of treatment. Further research is required in the form of large blinded randomized clinical trials with long-term followup to further characterize the clinical significance in comparison to placebo and standard systemic treatments in psoriasis patients, with and without diabetes.

We propose that dermatologists consider the prospective clinical utility of hypoglycemic agents in psoriasis patients especially with concomitant diabetes. An earlier consultation from endocrinology may be beneficial. Hypoglycemic agents are commonly used, safe, well tolerated, and are unlikely to be immunosuppressive [78-81]. For patients in which immunosuppression is contraindicated, off-label usage of hypoglycemic agents may be warranted to control severe psoriasis and improve quality of life while avoiding the toxic effects of other systemic therapies.

\section{Key Message}

Hypoglycemic agents may help treat psoriasis especially with coexisting diabetes or when immunosuppression is contraindicated.

\section{Disclosure Statement}

The authors have no relevant conflicts of interest to disclose. No funding was received for this study.

Dermatology 2017;233:23-29

DOI: $10.1159 / 000472149$ 


\section{References}

1 Griffiths CE, Barker JN: Pathogenesis and clinical features of psoriasis. Lancet 2007;370: 263-271.

2 Gelfand JM, Troxel AB, Lewis JD, et al: The risk of mortality in patients with psoriasis: results from a population-based study. Arch Dermatol 2007;143:1493-1499.

3 Armstrong AW, Harskamp CT, Armstrong EJ: Psoriasis and the risk of diabetes mellitus: a systematic review and meta-analysis. JAMA Dermatol 2013;149:84-91.

4 Wu CY, Shieh JJ, Shen JL, Liu YY, Chang YT, Chen YJ: Association between antidiabetic drugs and psoriasis risk in diabetic patients: results from a nationwide nested case-control study in Taiwan. J Am Acad Dermatol 2015; 72:123-130.

5 Henseler T, Christophers E: Disease concomitance in psoriasis. J Am Acad Dermatol 1995; 32:982-986.

6 Hogan AE, Tobin AM, Ahern T, et al: Glucagon-like peptide-1 (GLP-1) and the regulation of human invariant natural killer T cells: lessons from obesity, diabetes and psoriasis. Diabetologia 2011;54:2745-2754.

7 Buysschaert M, Tennstedt D, Preumont V: Improvement of psoriasis during exenatide treatment in a patient with diabetes. Diabetes Metab 2012;38:86-88.

8 Reid CT, Tobin AM, Ahern T, O'Shea D, Kirby B: Liraglutide in combination with acitretin for severe recalcitrant psoriasis. Br J Dermatol 2013;169:230-231.

9 Buysschaert M, Baeck M, Preumont V, et al: Improvement of psoriasis during glucagonlike peptide- 1 analogue therapy in type 2 diabetes is associated with decreasing dermal gammadelta T-cell number: a prospective case-series study. Br J Dermatol 2014;171: 155-161.

10 Faurschou A, Knop FK, Thyssen JP, Zachariae C, Skov L, Vilsboll T: Improvement in psoriasis after treatment with the glucagonlike peptide-1 receptor agonist liraglutide. Acta Diabetol 2014;51:147-150.

11 Ahern T, Tobin AM, Corrigan M, et al: Glucagon-like peptide-1 analogue therapy for psoriasis patients with obesity and type 2 diabetes: a prospective cohort study. J Eur Acad Dermatol Venereol 2013;27:1440-1443.

12 Faurschou A, Gyldenlove M, Rohde U, et al: Lack of effect of the glucagon-like peptide-1 receptor agonist liraglutide on psoriasis in glucose-tolerant patients - a randomized placebo-controlled trial. J Eur Acad Dermatol Venereol 2015;29:555-559.

13 Setty AR, Curhan G, Choi HK: Obesity, waist circumference, weight change, and the risk of psoriasis in women: Nurses' Health Study II. Arch Intern Med 2007;167:1670-1675.

14 Gisondi P, Del Giglio M, Di Francesco V, Zamboni M, Girolomoni G: Weight loss improves the response of obese patients with moderate-to-severe chronic plaque psoriasis to low-dose cyclosporine therapy: a random- ized, controlled, investigator-blinded clinical trial. Am J Clin Nutr 2008;88:1242-1247.

15 Faurschou A, Zachariae C, Skov L, Vilsboll T, Knop FK: Gastric bypass surgery: improving psoriasis through a GLP-1-dependent mechanism? Med Hypotheses 2011;77:1098-1101.

16 Lithell H, Bruce A, Gustafsson IB, et al: A fasting and vegetarian diet treatment trial on chronic inflammatory disorders. Acta Derm Venereol 1983;63:397-403.

17 Rucevic I, Perl A, Barisic-Drusko V, AdamPerl M: The role of the low energy diet in psoriasis vulgaris treatment. Coll Antropol 2003; 27(suppl 1):41-48.

18 List JF, He H, Habener JF: Glucagon-like peptide-1 receptor and proglucagon expression in mouse skin. Regul Pept 2006;134:149-157.

19 Faurschou A, Pedersen J, Gyldenlove M, et al: Increased expression of glucagon-like peptide-1 receptors in psoriasis plaques. Exp Dermatol 2013;22:150-152.

20 Van der Vliet HJ, von Blomberg BM, Nishi N, et al: Circulating V(alpha24+) Vbeta11+ NKT cell numbers are decreased in a wide variety of diseases that are characterized by autoreactive tissue damage. Clin Immunol 2001;100: 144-148.

21 Cameron AL, Kirby B, Griffiths CE: Circulating natural killer cells in psoriasis. Br J Dermatol 2003;149:160-164.

22 Cameron AL, Kirby B, Fei W, Griffiths CE: Natural killer and natural killer-T cells in psoriasis. Arch Dermatol Res 2002;294:363-369.

23 Chaudhuri A, Ghanim H, Vora M, et al: Exenatide exerts a potent antiinflammatory effect. J Clin Endocrinol Metab 2012;97:198-207.

24 Hattori Y, Jojima T, Tomizawa A, et al: A glucagon-like peptide-1 (GLP-1) analogue, liraglutide, upregulates nitric oxide production and exerts anti-inflammatory action in endothelial cells. Diabetologia 2010;53:2256-2263.

25 Kodera R, Shikata K, Kataoka HU, et al: Glucagon-like peptide-1 receptor agonist ameliorates renal injury through its anti-inflammatory action without lowering blood glucose level in a rat model of type 1 diabetes. Diabetologia 2011;54:965-978.

26 Nishioka T, Shinohara M, Tanimoto N, Kumagai C, Hashimoto K: Sitagliptin, a dipeptidyl peptidase-IV inhibitor, improves psoriasis. Dermatology 2012;224:20-21.

27 Lynch M, Tobin AM, Ahern T, O'Shea D, Kirby B: Sitagliptin for severe psoriasis. Clin Exp Dermatol 2014;39:841-842.

28 Nagai H, Fujiwara S, Takahashi Y, Nishigori C: Ameliorating effect of the novel dipeptidyl peptidase-4 inhibitor teneligliptin on psoriasis: a report of two cases. J Dermatol 2015;42: 1094-1097.

29 Kim SC, Schneeweiss S, Glynn RJ, Doherty M, Goldfine AB, Solomon DH: Dipeptidyl peptidase- 4 inhibitors in type 2 diabetes may reduce the risk of autoimmune diseases: a population-based cohort study. Ann Rheum Dis 2015;74:1968-1975.
30 Mas-Vidal A, Santos-Juanes J, Esteve-Martinez A, Caminal-Montero L, Coto-Segura P: Psoriasiform eruption triggered by a dipeptidyl peptidase IV inhibitor. Australas J Dermatol 2012;53:70-72.

31 Novelli M, Savoia P, Fierro MT, Verrone A, Quaglino P, Bernengo MG: Keratinocytes express dipeptidyl-peptidase IV (CD26) in benign and malignant skin diseases. Br J Dermatol 1996;134:1052-1056.

32 Van Lingen RG, van de Kerkhof PC, Seyger $\mathrm{MM}$, et al: CD26/dipeptidyl-peptidase IV in psoriatic skin: upregulation and topographical changes. Br J Dermatol 2008;158:12641272.

33 Van Lingen RG, Poll MK, Seyger MM, de Jong EM, van de Kerkhof PC, van Erp PE: Distribution of dipeptidyl-peptidase IV on keratinocytes in the margin zone of a psoriatic lesion: a comparison with hyperproliferation and aberrant differentiation markers. Arch Dermatol Res 2008;300:561-567.

34 Thielitz A, Reinhold D, Vetter R, et al: Inhibitors of dipeptidyl peptidase IV and aminopeptidase $\mathrm{N}$ target major pathogenetic steps in acne initiation. J Invest Dermatol 2007;127: 1042-1051.

35 Makdissi A, Ghanim H, Vora M, et al: Sitagliptin exerts an antiinflammatory action. J Clin Endocrinol Metab 2012;97:3333-3341.

36 Satoh-Asahara N, Sasaki Y, Wada H, et al: A dipeptidyl peptidase-4 inhibitor, sitagliptin, exerts anti-inflammatory effects in type 2 diabetic patients. Metabolism 2013;62:347-351.

37 Tremblay AJ, Lamarche B, Deacon CF, Weisnagel SJ, Couture P: Effects of sitagliptin therapy on markers of low-grade inflammation and cell adhesion molecules in patients with type 2 diabetes. Metabolism 2014;63:11411148.

38 Kim SJ, Nian C, McIntosh CH: Sitagliptin (MK0431) inhibition of dipeptidyl peptidase IV decreases nonobese diabetic mouse CD4+ T-cell migration through incretin-dependent and -independent pathways. Diabetes 2010; 59:1739-1750.

39 Ikeda T, Kumagai E, Iwata S, Yamakawa A: Soluble CD26/dipeptidyl peptidase IV enhances the transcription of IL- 6 and TNF-alpha in THP- 1 cells and monocytes. PLoS One 2013;8:e66520.

40 Ohnuma K, Hosono O, Dang NH, Morimoto C: Dipeptidyl peptidase in autoimmune pathophysiology. Adv Clin Chem 2011;53: 51-84.

41 Koren S, Shemesh-Bar L, Tirosh A, et al: The effect of sitagliptin versus glibenclamide on arterial stiffness, blood pressure, lipids, and inflammation in type 2 diabetes mellitus patients. Diabetes Technol Ther 2012;14:561567.

42 Choe EY, Cho Y, Choi Y, et al: The effect of DPP-4 inhibitors on metabolic parameters in patients with type 2 diabetes. Diabetes Metab J 2014;38:211-219. 
43 Raynaud F, Bauvois B, Gerbaud P, Evain-Brion $\mathrm{D}$ : Characterization of specific proteases associated with the surface of human skin fibroblasts, and their modulation in pathology. J Cell Physiol 1992;151:378-385.

44 Bock O, Kreiselmeyer I, Mrowietz U: Expression of dipeptidyl-peptidase IV (CD26) on $\mathrm{CD} 8+\mathrm{T}$ cells is significantly decreased in patients with psoriasis vulgaris and atopic dermatitis. Exp Dermatol 2001;10:414-419.

45 Lee SA, Kim YR, Yang EJ, et al: CD26/DPP4 levels in peripheral blood and $\mathrm{T}$ cells in patients with type 2 diabetes mellitus. J Clin Endocrinol Metab 2013;98:2553-2561.

46 Bengsch B, Seigel B, Flecken T, Wolanski J, Blum HE, Thimme R: Human Th17 cells express high levels of enzymatically active dipeptidylpeptidase IV (CD26). J Immunol 2012;188:5438-5447.

47 Pershadsingh HA, Sproul JA, Benjamin E, Finnegan J, Amin NM: Treatment of psoriasis with troglitazone therapy. Arch Dermatol 1998;134:1304-1305.

48 Ellis CN, Varani J, Fisher GJ, et al: Troglitazone improves psoriasis and normalizes models of proliferative skin disease: ligands for peroxisome proliferator-activated receptor-gamma inhibit keratinocyte proliferation. Arch Dermatol 2000;136:609-616.

49 Robertshaw H, Friedmann PS: Pioglitazone: a promising therapy for psoriasis. Br J Dermatol 2005; 152:189-191.

50 Pershadsingh HA, Benson SC, Ellis CN: Improvement in psoriasis with rosiglitazone in a diabetic and a nondiabetic patient. Skinmed 2005;4:386-390.

51 Mittal R, Malhotra S, Pandhi P, Kaur I, Dogra S: Efficacy and safety of combination acitretin and pioglitazone therapy in patients with moderate to severe chronic plaque-type psoriasis: a randomized, double-blind, placebocontrolled clinical trial. Arch Dermatol 2009; 145:387-393.

52 Lajevardi V, Hallaji Z, Daklan S, Abedini R, Goodarzi A, Abdolreza M: The efficacy of methotrexate plus pioglitazone vs methotrexate alone in the management of patients with plaque-type psoriasis: a single-blinded randomized controlled trial. Int J Dermatol 2015; 54:95-101.

53 Hafez VG, Bosseila M, Abdel Halim MR, Shaker OG, Kamal M, Kareem HS: Clinical effects of pioglitazone, an insulin sensitizing drug, on psoriasis vulgaris and its co-morbidities: a double blinded randomized controlled trial. J Dermatolog Treat 2015;26:208-214.

54 Itoh S, Kanazuka A, Akimoto T: Combined treatment with ursodeoxycholic acid and pioglitazone in a patient with NASH associated with type 2 diabetes and psoriasis. Dig Dis Sci 2003;48:2182-2186.

55 Shafiq N, Malhotra S, Pandhi P, Gupta M, Kumar B, Sandhu K: Pilot trial: pioglitazone versus placebo in patients with plaque psoriasis (the P6). Int J Dermatol 2005;44:328-333.
56 Singh S, Bhansali A: Randomized placebo control study of insulin sensitizers (metformin and pioglitazone) in psoriasis patients with metabolic syndrome (topical treatment cohort). BMC Dermatol 2016;16:12.

57 Bongartz T, Coras B, Vogt T, Scholmerich J, Muller-Ladner U: Treatment of active psoriatic arthritis with the PPARgamma ligand pioglitazone: an open-label pilot study. Rheumatology (Oxford) 2005;44:126-129.

58 Heydendael VM, Spuls PI, Opmeer BC, et al: Methotrexate versus cyclosporine in moderate-to-severe chronic plaque psoriasis. $\mathrm{N}$ Engl J Med 2003;349:658-665.

59 Brauchli YB, Jick SS, Curtin F, Meier CR: Association between use of thiazolidinediones or other oral antidiabetics and psoriasis: a population based case-control study. J Am Acad Dermatol 2008;58:421-429.

60 Ellis CN, Barker JN, Haig AE, Parker CA, Daly S, Jayawardene DA: Placebo response in two long-term randomized psoriasis studies that were negative for rosiglitazone. Am J Clin Dermatol 2007;8:93-102.

61 Malhotra A, Shafiq N, Rajagopalan S, Dogra S, Malhotra S: Thiazolidinediones for plaque psoriasis: a systematic review and meta-analysis. Evid Based Med 2012;17:171-176.

62 Kuenzli S, Saurat JH: Effect of topical PPARbeta/delta and PPARgamma agonists on plaque psoriasis. A pilot study. Dermatology 2003;206:252-256.

63 Bhagavathula N, Nerusu KC, Lal A, et al: Rosiglitazone inhibits proliferation, motility, and matrix metalloproteinase production in keratinocytes. J Invest Dermatol 2004;122:130139.

64 Venkatraman MS, Chittiboyina A, Meingassner J, et al: Alpha-lipoic acid-based PPARgamma agonists for treating inflammatory skin diseases. Arch Dermatol Res 2004;296: 97-104.

65 Demerjian M, Man MQ, Choi EH, et al: Topical treatment with thiazolidinediones, activators of peroxisome proliferator-activated receptor-gamma, normalizes epidermal homeostasis in a murine hyperproliferative disease model. Exp Dermatol 2006;15:154160.

66 Bhagavathula N, Nerusu KC, Reddy M, et al: BP-1107 [\{2-[4-(2,4-dioxo-thiazolidin-5ylmethyl)-phenoxy]-ethyl\}-methyl-amide]: a novel synthetic thiazolidinedione that inhibits epidermal hyperplasia in psoriatic skinsevere-combined immunodeficient mouse transplants after topical application. J Pharmacol Exp Ther 2005;315:996-1004.

67 Gupta M, Mahajan VK, Mehta KS, Chauhan PS, Rawat R: Peroxisome proliferator-activated receptors (PPARs) and PPAR agonists: the "future" in dermatology therapeutics? Arch Dermatol Res 2015;307:767-780.

68 Giorgini AE, Beales PE, Mire-Sluis A, Scott D, Liddi R, Pozzilli P: Troglitazone exhibits immunomodulatory activity on the cytokine production of activated human lymphocytes. Horm Metab Res 1999;31:1-4.
69 Jiang C, Ting AT, Seed B: PPAR-gamma agonists inhibit production of monocyte inflammatory cytokines. Nature 1998;391:82-86.

70 Yang XY, Wang LH, Chen T, et al: Activation of human T lymphocytes is inhibited by peroxisome proliferator-activated receptor gamma (PPARgamma) agonists. PPARgamma co-association with transcription factor NFAT. J Biol Chem 2000;275:4541-4544.

71 Gyldenlove M, Storgaard H, Holst JJ, Vilsboll T, Knop FK, Skov L: Patients with psoriasis are insulin resistant. J Am Acad Dermatol 2015;72:599-605.

72 Koca R, Altinyazar HC, Yenidunya S, Tekin NS: Psoriasiform drug eruption associated with metformin hydrochloride: a case report. Dermatol Online J 2003;9:11.

73 Sag D, Carling D, Stout RD, Suttles J: Adenosine $5^{\prime}$-monophosphate-activated protein kinase promotes macrophage polarization to an anti-inflammatory functional phenotype. J Immunol 2008;181:8633-8641.

74 Krysiak R, Okopien B: Lymphocyte-suppressing and systemic anti-inflammatory effects of high-dose metformin in simvastatin-treated patients with impaired fasting glucose. Atherosclerosis 2012;225:403-407.

75 Banaszewska B, Pawelczyk L, Spaczynski RZ, Duleba AJ: Comparison of simvastatin and metformin in treatment of polycystic ovary syndrome: prospective randomized trial. J Clin Endocrinol Metab 2009;94:4938-4945.

76 Li W, Ma W, Zhong H, Liu W, Sun Q: Metformin inhibits proliferation of human keratinocytes through a mechanism associated with activation of the MAPK signaling pathway. Exp Ther Med 2014;7:389-392.

77 Liu Y, Yang F, Ma W, Sun Q: Metformin inhibits proliferation and proinflammatory cytokines of human keratinocytes in vitro via mTOR-signaling pathway. Pharm Biol 2016; 54:1173-1178.

78 Stein SA, Lamos EM, Davis SN: A review of the efficacy and safety of oral antidiabetic drugs. Expert Opin Drug Saf 2013;12:153175.

79 Price JD, Linder G, Li WP, et al: Effects of short-term sitagliptin treatment on immune parameters in healthy individuals, a randomized placebo-controlled study. Clin Exp Immunol 2013;174:120-128.

80 Scheen AJ: Safety of dipeptidyl peptidase- 4 inhibitors for treating type 2 diabetes. Expert Opin Drug Saf 2015;14:505-524.

81 Goodwin SR, Reeds DN, Royal M, Struthers H, Laciny E, Yarasheski KE: Dipeptidyl peptidase IV inhibition does not adversely affect immune or virological status in HIV infected men and women: a pilot safety study. J Clin Endocrinol Metab 2013;98:743-751.

82 Garg R, Chen W, Pendergrass M: Acute pancreatitis in type 2 diabetes treated with exenatide or sitagliptin: a retrospective observational pharmacy claims analysis. Diabetes Care 2010;33:2349-2354. 